\title{
RELATIONSHIP BETWEEN WORKPLACE SUPPORT AND BREASTFEEDING SELF-EFFICACY WORKING MOTHERS IN PUSKESMAS JETIS YOGYAKARTA
}

\author{
Nurul Kurniati11), Djauhar Ismail2), Herlin Fitriani Kurniawati1) \\ 1) Aisyiyah University at Yogyakarta \\ 2) Gadjah Mada University
}

\begin{abstract}
BACKGROUND: According to WHO, less than 40\% of infants worldwide were exclusively breastfed. In Indonesia, only $48.6 \%$ and Yogyakarta $42.70 \%$ of infants were exclusively breastfed. This breastfeeding level is far below the national target of $80 \%$ exclusive breastfeeding for infants. Support from the workplace may increase breastfeeding self-efficacy among mothers with infant. This study aimed to determine the relationship between workplace support and breastfeeding self-efficacy among mothers with infant.

SUBJECT AND METHODS: This study was a cross sectional study conducted in Yogyakarta. A sample of 87 mothers who had infants under 6 months from Puskesmas Jetis, Yogyakarta, was selected for this study. The dependent variable was breastfeeding self-efficacy. The independent variable was workplace support. A questionnaire was developed to measure these variables. Bivariate analysis involving Odds Ratio and Chi Square test was used to analyze the data.

RESULT: Workplace support increased breastfeeding self-efficacy. Mothers with support from the workplace were 1.59 times more likely to have strong breastfeeding self-efficacy than those without support from the workplace $(\mathrm{OR}=1.59 ; \mathrm{p}=0.013)$.

CONCLUSION: Workplace support increases breastfeeding self-efficacy. It is suggested that every workplace provides support to working mothers with infants (e.g. breastfeeding corner) to increase breastfeeding selfefficacy.
\end{abstract}

Keywords: workplace support, breastfeeding, self-efficacy, working mother, infants 